\title{
Produtividade e acúmulo de nitrato nos frutos de abobrinha em função da adubação nitrogenada
}

\author{
Mônica Lima Alves Pôrto ( ${ }^{*}$ ); Mário Puiatti ( $\left.{ }^{1}\right)$; Paulo Cezar Rezende Fontes ('); Paulo Roberto \\ Cecon ( ${ }^{2}$ ); Jailson do Carmo Alves (3); Jandeilson Alves de Arruda ( $\left.{ }^{4}\right)$ \\ (') Universidade Federal de Viçosa (UFV), Departamento de Fitotecnia, Av. P.H. Holfs, s/n, 36570-000 Viçosa (MG), Brasil. \\ (2) UFV, Departamento de Estatística, Viçosa (MG), Brasil. \\ (3) Instituto Federal de Educação, Ciência e Tecnologia de Alagoas (IFAL), Rod. BR 316, km 87,5, 57500-000 Santana do \\ Ipanema (AL), Brasil. \\ (4) Instituto Federal de Educação, Ciência e Tecnologia da Paraíba (IFPB), Acesso Rod. PB 151, s/n, 58187-000 Picuí (PB), Brasil. \\ (*) Autora correspondente: monicalporto@yahoo.com.br
}

Recebido: 5/jun./2011; Aceito: 4/fev./2012

\section{Resumo}

Apesar da importância da abobrinha em termos comerciais e alimentícios, poucos estudos têm sido realizados em relação à adubação nitrogenada da cultura. O objetivo deste trabalho foi avaliar a produtividade e o acúmulo de nitrato nos frutos da abobrinha (cv. Caserta) em função da adubação nitrogenada. O experimento foi desenvolvido no delineamento de blocos casualizados, com cinco doses de N (0; 50; 100; 200 e $\left.400 \mathrm{~kg} \mathrm{ha}^{-1}\right)$, com quatro repetições. Foram avaliados: número de frutos por planta, massa média de frutos, produtividade da cultura e acúmulo de nitrato nos frutos. Todas as características avaliadas foram significativamente influenciadas $(p<0,01)$ pelas doses de $\mathrm{N}$. Os valores máximos do número de frutos por planta (7,7 unidades), massa média de frutos ( $\left.240 \mathrm{~g} \mathrm{fruto}^{-1}\right)$ e produtividade de frutos $\left(29,88 \mathrm{t} \mathrm{ha}^{-1}\right)$ foram obtidos com 323 , 265 e $331 \mathrm{~kg} \mathrm{ha}^{-1}$ de N, respectivamente. A dose de máxima eficiência econômica de N para a cultura da abobrinha foi de $322 \mathrm{~kg} \mathrm{ha}^{-1}$, resultando em uma produtividade de frutos de 29,86 t ha-1. O teor de nitrato nos frutos proporcionou incremento linear em função das doses de $\mathrm{N}$ verificando-se, com a dose máxima, o teor na matéria fresca de fruto de $162 \mathrm{mg}_{\mathrm{kg}}^{-1} \mathrm{de}$ nitrato, valor que não representa risco para saúde humana.

Palavras-chave: Cucurbita pepo, nitrogênio, qualidade, rendimento, eficiência econômica.

\section{Zucchini yield and nitrate accumulation in fruits as a function of the nitrogen fertilization}

\begin{abstract}
Despite Zucchini nutritional and commercial importance, few studies have been carried out with the nitrogen fertilization of the culture. The objective of this research was to evaluate the zucchini yield (cv. Caserta) and nitrate accumulation in the fruits as a function of the nitrogen fertilization. The experiment was set in a randomized block design with five rates of mineral $\mathrm{N}(0$; 50; 100; 200 and $400 \mathrm{~kg} \mathrm{ha}^{-1}$ ), with four replications. The number of fruits per plant, average fruit mass, fruit yield and nitrate accumulation in the fruits were significantly affected $(p<0.01)$ by $\mathrm{N}$ rates. The maximum number of fruits per plant ( 7.7 units), mean fruit weight (240 $\left.\mathrm{g} \mathrm{fruit}^{-1}\right)$ and fruit yield $\left(29.88 \mathrm{t} \mathrm{ha}^{-1}\right)$ were obtained with 323, 265 and $331 \mathrm{~kg} \mathrm{ha}^{-1}$ of N, respectively. The maximum economical efficiency rate of $\mathrm{N}$ for the culture of the zucchini was $322 \mathrm{~kg} \mathrm{ha}^{-1}$, resulting in a fruit yield of 29.86 $\mathrm{t} \mathrm{ha}^{-1}$. The nitrate content in the zucchini fruits presented linear increment as a function of $\mathrm{N}$ rates. At the highest $\mathrm{N}$ rate, the nitrate content in the fruit fresh matter was $162 \mathrm{mg} \mathrm{kg}^{-1}$. This nitrate contents value does not represent risk for human health.
\end{abstract}

Key words: Cucurbita pepo, nitrogen, quality, yield, economical efficiency.

\section{INTRODUÇÃO}

A abobrinha (Cucurbita pepo L.) é uma planta da família das cucurbitáceas que tem a regiáo central do México e sul dos Estados Unidos da América como centro de diversidade. No Brasil, também é conhecida como abóbora de moita, abobrinha italiana, caserta, abobrinha de tronco (Filgueira, 2008).

A abobrinha situa-se entre as dez hortaliças de maior valor econômico, com importância econômica elevada, principalmente no centro e sul do Brasil (CARPES et al.,
2008). A produtividade média no Brasil oscila em torno de 8 a 10 t ha $^{-1}$ (Filgueira, 2008), todavia essa é muito variável em funçáo do nível de tecnologias aplicadas e das características peculiares de cada cultivar (PuiatTi e Silva, 2005).

A adubação nitrogenada é fundamental para a obtenção de adequada produtividade. A dose adequada de nitrogênio é variável de acordo com vários fatores entre os quais a produtividade almejada, cultivar, técnicas de manejo, fonte e condiçóes edafoclimáticas. Apesar da relativa importância econômica e nutricional da 
abobrinha, poucos estudos têm sido realizados em relaçáo à fertilização da cultura, sobretudo a nitrogenada. $\mathrm{Na}$ literatura, a maioria dos trabalhos relativos à fertilização aborda outras espécies de cucurbitáceas, de maior valor econômico, tais como melão e melancia.

O nitrogênio é um nutriente que influencia os processos envolvidos no crescimento e desenvolvimento das plantas, alterando a relaçâo fonte-dreno e, consequentemente, a distribuição de assimilados entre órgãos vegetativos e reprodutivos. Em cucurbitáceas, o aumento da dose de $\mathrm{N}$, até determinado limite, proporciona incremento na área foliar da planta; portanto, exerce efeito na produção de fotoassimilados e, consequentemente, na produção de frutos (Queiroga et al., 2007).

Resultados de trabalhos com as culturas do melão (Queiroga et al., 2007), melancia (ANDrade Junior et al., 2006) e maxixe (Oliveira et al., 2008) têm demonstrado aumentos no número e na massa média de fruto e, consequentemente, da produtividade, com a elevação das doses de N. Entretanto, a adubação nitrogenada se constitui atualmente em assunto polêmico, pois quando aplicada em excesso pode resultar na redução da qualidade e segurança nutricional devido ao acúmulo de nitrato. $\mathrm{O}$ nitrato, quando ingerido em grandes quantidades, pode causar graves consequências à saúde, como formação de nitrosaminas, substância potencialmente carcinogênica, além da metahemoglobinemia ou sangue azul que reduz o transporte de oxigênio no sangue (Boink e Speijers, 2001; Addiscott e Benjamin, 2004).

Algumas estimativas revelam que as hortaliças correspondem ao grupo de alimentos que mais contribui para a ingestão de nitrato pelo homem, sendo responsáveis por cerca de $72 \%$ e $94 \%$ da ingestão diária (TurAzi et al., 2006). De forma geral, nas folhosas como alface, espinafre, repolho, entre outras, nota-se tendência para acumular altos teores de nitrato em suas folhas (BENINNI et al., 2002; Mantovani et al., 2005), havendo grande interesse em monitorar o teor de nitrato nestas plantas (BENINNI et al., 2002). Já em hortaliças de flores e frutos, a exemplo da couve-flor e tomate, geralmente, há tendência de menor acúmulo de nitrato (Fytianos e Zarogiannis, 1999). $\mathrm{Na}$ literatura, não foram constatados dados referentes ao acúmulo de nitrato em frutos de abobrinha, bem como a influência da adubação nitrogenada sobre esse acúmulo.

O objetivo deste trabalho foi avaliar a produtividade e o acúmulo de nitrato nos frutos da abobrinha em função da adubação nitrogenada.

\section{MATERIAL E MÉTODOS}

O experimento foi desenvolvido em Argissolo VermelhoAmarelo Câmbico, textura franco argilo-arenosa, com as seguintes características químicas (camada de 0-20 cm): $\mathrm{pH}$ em $\mathrm{H}_{2} \mathrm{O}=6,8 ; \mathrm{K}=148,0 \mathrm{mg} \mathrm{dm}^{-3} ; \mathrm{P}=153,4 \mathrm{mg} \mathrm{dm}^{-3}$;
$\mathrm{Ca}=4,1 \mathrm{cmol} \mathrm{dm}^{-3} ; \mathrm{Mg}=0,7 \mathrm{cmol} \mathrm{dm}^{-3} ; \mathrm{S}=19,8 \mathrm{mg} \mathrm{dm}^{-3} ;$ $\mathrm{Al}=0,0 \mathrm{cmol} \mathrm{dm}^{-3} ; \mathrm{H}+\mathrm{Al}=1,49 \mathrm{cmol} \mathrm{dm}^{-3}$ e matéria orgânica $=1,5 \mathrm{dag} \mathrm{kg}^{-1}$.

As mudas de abobrinha (cv. Caserta) foram produzidas em ambiente protegido, em bandejas de isopor de 128 células, utilizando-se substrato comercial. A semeadura foi realizada em 23/9/2008, e as mudas transplantadas para o local de cultivo em 9/10/2008, quando estavam com duas folhas definitivas. O experimento foi constituído de cinco doses de N $\left(0 ; 50 ; 100 ; 200\right.$ e $\left.400 \mathrm{~kg} \mathrm{ha}^{-1}\right)$, no delineamento experimental de blocos casualizados, com quatro repetiçóes. Utilizou-se o espaçamento de $1,0 \mathrm{~m} \mathrm{x}$ $0,60 \mathrm{~m}$, contendo uma planta por cova. A parcela experimental foi constituída de 20 plantas, dispostas em quatro fileiras com cinco plantas cada uma. A área útil da parcela correspondeu àquela ocupada pelas seis plantas centrais das fileiras centrais.

A adubação mineral ( $\mathrm{P}, \mathrm{K}$ e micronutrientes) foi determinada mediante análise química do solo e recomendaçôes para a cultura no Estado de Minas Gerais (CARrijo et al., 1999). Foram aplicados: $225 \mathrm{~kg} \mathrm{ha}^{-1}$ de superfosfato simples; $100 \mathrm{~kg} \mathrm{ha}^{-1}$ de cloreto de potássio; $15 \mathrm{~kg} \mathrm{ha}^{-1}$ de sulfato de zinco; $10 \mathrm{~kg} \mathrm{ha}^{-1}$ de bórax; $10 \mathrm{~kg} \mathrm{ha}^{-1}$ de sulfato de cobre e $0,5 \mathrm{~kg} \mathrm{ha}^{-1}$ de molibdato de amônio. As doses de $\mathrm{N}$ foram aplicadas na forma de sulfato de amônio em razão de essa ser a principal fonte de adubo nitrogenado empregada na cultura. Além disso, no solo da área empregada havia disponibilidade alta de S (Alvarez V. et al., 1999), além de ter sido veiculado, aproximadamente, $30 \mathrm{~kg} \mathrm{ha}^{-1}$ desse nutriente como elemento acompanhante do superfosfato simples, sulfato de zinco e sulfato de cobre. Portanto, essas condições são suficientes para eliminar possíveis interferências do $\mathrm{S}$ adicionado mediante a aplicação das doses crescentes de $\mathrm{N}$ na forma de sulfato de amônio.

Aos 10 dias antes do transplante das mudas, foram aplicadas as totalidades de $\mathrm{P}$ e de micronutrientes, além de $40 \%$ do $\mathrm{K}$ e de $30 \%$ da dose de $\mathrm{N}$ avaliada. O restante do $\mathrm{N}$ e do $\mathrm{K}$ foi aplicado em duas coberturas, ao redor das plantas, seguido de irrigação. A primeira cobertura foi realizada aos 15 dias após o transplante e a segunda, 25 dias após a primeira (Puiatti e Silva, 2005).

O preparo do solo constou de araçáo, gradagem e abertura de sulcos distanciados de $1,0 \mathrm{~m}$ e a profundidade de $0,25 \mathrm{~cm}$. Os adubos de plantio foram distribuídos nos sulcos, incorporados e cobertos. Durante o desenvolvimento da cultura foram realizadas capinas manuais, com auxílio de enxada, e irrigaçóes periódicas por aspersão convencional, de acordo com as necessidades da cultura. Assim, não houve competição por plantas daninhas nem estresse hídrico durante o desenvolvimento.

Os frutos foram colhidos a cada dois dias, de forma manual, no estádio imaturo, quando as características comerciais da cultivar eram as seguintes: 15 e $20 \mathrm{~cm}$ de comprimento, 4 a $6 \mathrm{~cm}$ de diâmetro e com massa média 
de 200 a $250 \mathrm{~g}$ (com exceção dos tratamentos onde foram aplicadas as menores doses de $\mathrm{N}$, e cujos frutos não alcançaram tais características). O número de frutos por planta foi obtido pela contagem de todos os frutos colhidos divididos pelo número de plantas, em cada tratamento. A massa média de fruto correspondeu à razão entre produção total de frutos e número de frutos colhidos, em cada tratamento. Também foi estimada a produtividade em kg ha ${ }^{-1}$.

Para determinaçáo do teor de nitrato nos frutos, foram empregadas amostras de frutos colhidos no pico produtivo da cultura. Os frutos com tamanho comercial foram coletados, lavados em água de torneira e, posteriormente, em água deionizada. Em seguida, foram seccionados em cubos, pesados e colocados para secar em estufa de circulação forçada de ar a $75^{\circ} \mathrm{C}$, até atingirem massa constante. Após a pesagem foi calculado o teor de matéria seca. Posteriormente, amostras secas de fruto foram trituradas em moinho tipo Wiley e tamisadas em peneira de 20 mesh. Na matéria seca dos frutos, após a extração com água em banho-maria a $45{ }^{\circ} \mathrm{C}$, durante uma hora, determinaram-se as concentraçóes de $\mathrm{N}_{-} \mathrm{NO}_{3}{ }^{-}$por colorimetria, em espectrofotômetro a $410 \mathrm{~nm}$ (CATALDo et al., 1975). Com base nos teores de matéria seca e fresca dos frutos, os teores de nitrato na matéria seca foram convertidos para teores na matéria fresca.

Os resultados foram submetidos à análise de variância, com desdobramento do efeito das doses de $\mathrm{N}$ em regressão, considerando-se até $\mathrm{p}<0,05$. A escolha do modelo, além da significância do ajuste do $\left(\mathrm{R}^{2}\right)$, levou em consideração a explicação biológica do fenômeno em estudo. As análises estatísticas foram realizadas no software SAEG, versão 9.1 (SAEG, 2007).

A dose de máxima eficiência econômica de $\mathrm{N}$ foi calculada igualando-se a derivada primeira da equação de regressão referente à produtividade de frutos de abobrinha em função das doses de $\mathrm{N}$ à relação entre preços do insumo $\left(\mathrm{R} \$ \mathrm{~kg}^{-1}\right.$ de $\left.\mathrm{N}\right)$ e do produto $\left(\mathrm{R} \$ \mathrm{~kg}^{-1}\right.$ de frutos de abobrinha) (RAIJ, 1991). No cálculo, consideraram-se os preços médios de comercializaçáo do insumo e do produto empregados no Estado de Minas Gerais, no ano do experimento (2008), que foram de $\mathrm{R} \$ 3,50$ por $\mathrm{kg}^{-1} \mathrm{de} \mathrm{N}$ (empregando como fonte o sulfato de amônio) (CONAB, 2011) e $\mathrm{R} \$ 0,80$ por $\mathrm{kg}^{-1}$ de frutos de abobrinha - preço médio de frutos de abobrinha, considerando o valor médio de comercialização nas seis unidades da CEASA-MG (CEASA-MG, 2011).

\section{RESULTADOS E DISCUSSÃO}

A cultura da abobrinha respondeu positivamente à adubaçáo nitrogenada, uma vez que todas as características avaliadas foram influenciadas $(\mathrm{p}<0,01)$ pelas doses de $\mathrm{N}$ (Figuras $1 \mathrm{a} 4$ ).

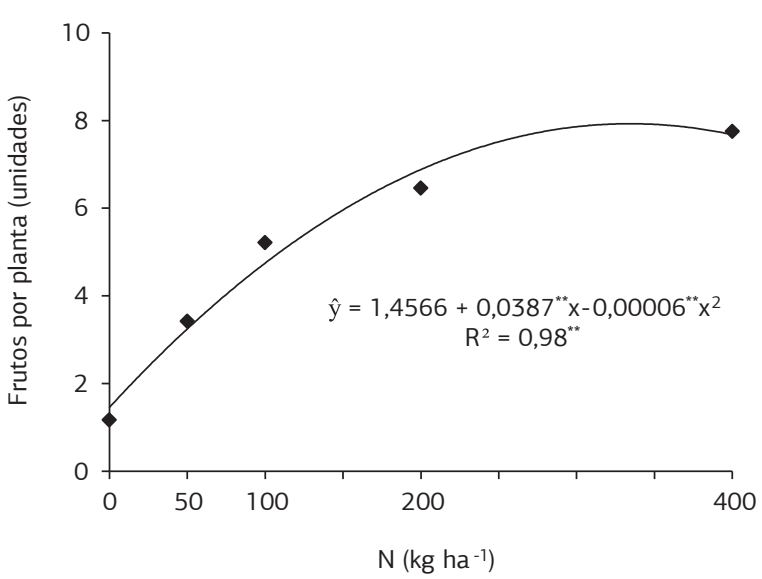

Figura 1. Número de frutos por planta de abobrinha em função de doses de N. Valores médios de quatro repetiçôes. ${ }^{* *}$ Significativo a $\mathrm{p}<0,01$, pelo teste $t$.

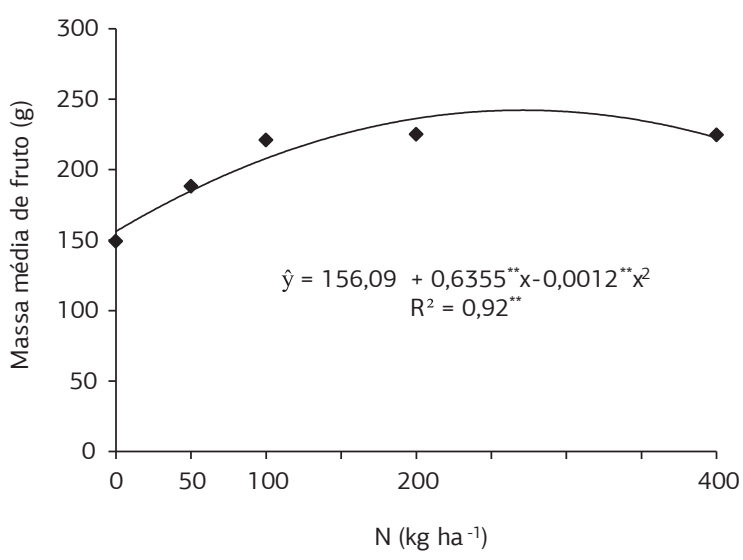

Figura 2. Massa média de fruto de abobrinha em função de doses de N. Valores médios de quatro repetiçóes. ${ }^{* *}$ Significativo a $\mathrm{p}<0,01$, pelo teste $\mathrm{t}$.

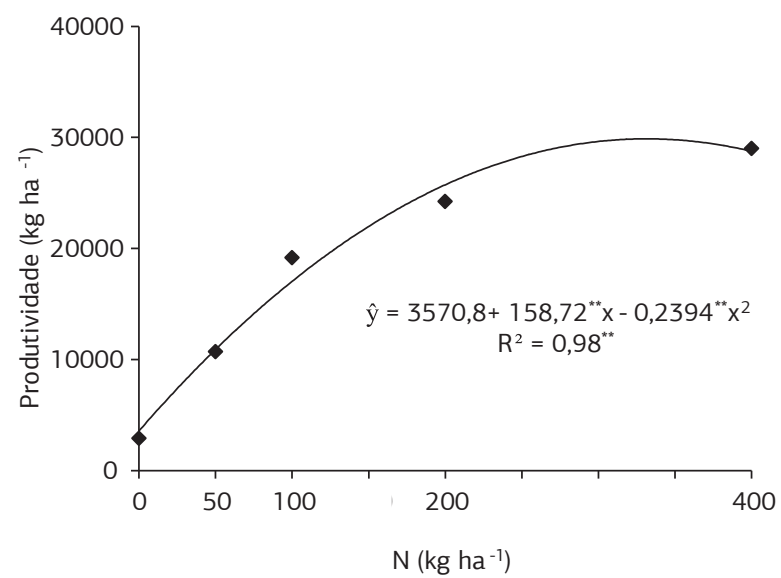

Figura 3. Produtividade de frutos de abobrinha em função de doses de N. Valores médios de quatro repetiçôes. ${ }^{* *}$ Significativo a $\mathrm{p}<0,01$, pelo teste $\mathrm{t}$. 


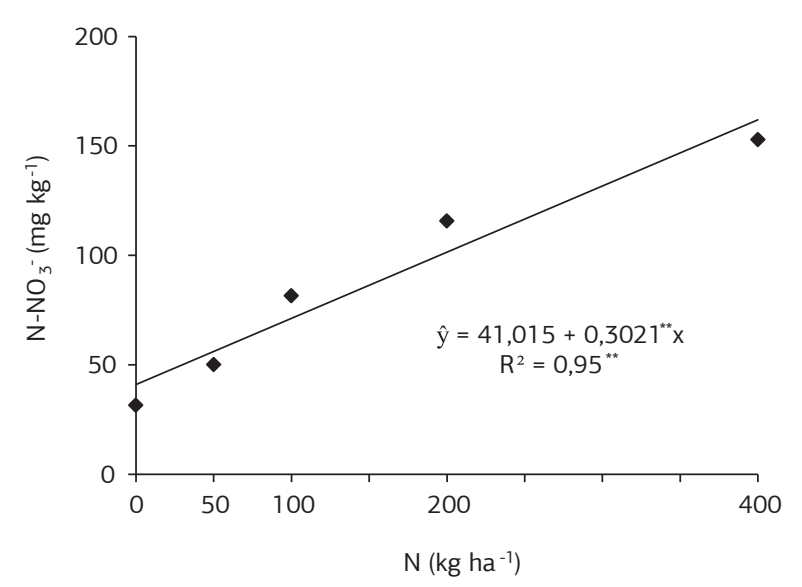

Figura 4. Teor de nitrato $\left(\mathrm{N}-\mathrm{NO}_{3}^{-}\right)$na matéria fresca de frutos de abobrinha em funçáo de doses de $\mathrm{N}$. Valores médios de quatro repetiçôes. ${ }^{* *}$ Significativo a $\mathrm{p}<0,01$, pelo teste $\mathrm{t}$.

Os valores das características número de frutos por planta, massa média de frutos e produtividade de frutos, em função do incremento das doses de $\mathrm{N}$, ajustaram-se ao modelo quadrático (Figuras 1 a 3). O número máximo de frutos por planta foi de 7,7 unidades, obtido com a dose estimada de $323 \mathrm{~kg} \mathrm{ha}^{-1}$ de $\mathrm{N}$; esse resultado corresponde a um incremento de 4,3 vezes em relação à testemunha.

Quanto à massa média de frutos (Figura 2), a dose estimada de $265 \mathrm{~kg} \mathrm{ha}^{-1}$ de $\mathrm{N}$ foi responsável pela máxima massa média de frutos $\left(240 \mathrm{~g}\right.$ fruto $\left.^{-1}\right)$. Esse resultado corresponde ao incremento de 0,54 vezes em relaçáo à testemunha.

A máxima produtividade de frutos de abobrinha (29.878 $\mathrm{kg} \mathrm{ha}^{-1}$ ) foi obtida com a dose estimada de $331 \mathrm{~kg} \mathrm{ha}^{-1}$ de N (Figura 3). Esse resultado corresponde ao incremento de 7,4 vezes, em relaçáo à testemunha.

$\mathrm{O} \mathrm{N}$ influencia processos envolvidos no crescimento e desenvolvimento das plantas, alterando a relação fonte-dreno e, consequentemente, a distribuição de assimilados entre órgãos vegetativos e reprodutivos. Em cucurbitáceas, o aumento da dose de $\mathrm{N}$, até determinado limite, proporciona incremento na área foliar da planta; portanto, exerce efeito na produção de fotoassimilados e, consequentemente, na produção de frutos (QueIroga et al., 2007). Os resultados constantes desse trabalho indicam que o efeito da adubação nitrogenada sobre a produção da abobrinha ocorreu em função do aumento do número e da massa média de frutos sendo, portanto, estas características determinantes na produtividade da cultura. Resultados semelhantes foram obtidos com outras cucurbitáceas, como melancia (ANDRADE Junior et al., 2006), melão (Queiroga et al., 2007) e maxixe (Oliveira et al., 2008), com aumento de produtividade como resultado do aumento do número de frutos por planta e da massa média de fruto, obtidos com a elevaçáo das doses de $\mathrm{N}$.
Para o meláo cantaloupe, Coelho et al. (2003) verificaram que a dose de $\mathrm{N}$ responsável pela máxima produção comercial de frutos foi de 312 e $344 \mathrm{~kg} \mathrm{ha}^{-1}$ para o cultivo em ambiente protegido e no campo, respectivamente. Ainda para o meláo cantaloupe em ambiente protegido, Queiroga et al. (2007) verificaram que a dose de $309,7 \mathrm{~kg} \mathrm{ha}^{-1}$ foi a responsável pela máxima produção comercial de frutos. Tais doses de $\mathrm{N}$ são semelhantes à observada neste trabalho como a responsável pela máxima produtividade de frutos de abobrinha, que foi de $331 \mathrm{~kg} \mathrm{ha}^{-1} \mathrm{de} \mathrm{N}$.

Para o cultivo da abobrinha no Estado de Minas Gerais, é recomendado o emprego de dose de $120 \mathrm{~kg} \mathrm{ha}^{-1}$ de $\mathrm{N}$ para uma produtividade de frutos esperada de 15 a $18 \mathrm{t} \mathrm{ha}^{-1}$ (CARrijo et al., 1999). Com a dose recomendada em Minas Gerais, a produtividade estimada seria $19,2 \mathrm{t} \mathrm{ha}^{-1}$. Esse valor é apenas $65 \%$ da máxima produtividade obtida no presente estudo. Portanto, nas condiçôes em que esse trabalho foi realizado e pelos resultados, verifica-se que é possível alcançar maior produtividade da abobrinha com a aplicação de maior dose de $\mathrm{N}$ do que a recomendada para Minas Gerais, permitindo melhor exploração do potencial produtivo da cultura. É importante mencionar que a época de plantio e condução do experimento (Primavera) pode ter contribuído para a alta produtividade obtida, uma vez que nessa época a população de afídeos (vetores de viroses) costuma ser menor. Assim, teve-se baixa incidência de viroses, fator limitante à produção da abobrinha em diversas regiôes no Brasil, o que deve ter contribuído para o elevado desempenho produtivo da cultura.

Atualmente, a sustentabilidade é o grande desafio da produção agrícola, sendo a otimizaçáo dos fatores de produção de fundamental importância para alcançar a produção sustentável, principalmente no que se refere ao uso de fertilizantes. Diante desse aspecto, é interessante mensurar a dose de máxima eficiência econômica dos fertilizantes.

No presente trabalho, a fórmula obtida para a determinação da dose de máxima eficiência econômica de $\mathrm{N}$ foi:

$$
\text { Dose de } \mathrm{N}=\frac{(158,72-\mathrm{Y})}{2 \times 0,2394}
$$

Em que: Y é a relação entre os preços do insumo e do produto.

Dessa forma, a dose de máxima eficiência econômica de $\mathrm{N}$ para a produtividade da cultura da abobrinha foi de $322 \mathrm{~kg} \mathrm{ha}^{-1}$, para $\mathrm{Y}=4,375$, com produtividade de frutos de aproximadamente $29.857 \mathrm{~kg} \mathrm{ha}^{-1}$, o que representa incremento de 7,4 vezes em relação à testemunha. A dose de máxima eficiência econômica de $\mathrm{N}$ foi próxima daquela responsável pela máxima produtividade de frutos de abobrinha (97\% da mesma), indicando que na cultura da abobrinha há elevada resposta em termos econômicos ao emprego de $\mathrm{N}$. 
O teor de nitrato nos frutos de abobrinha propiciou incremento linear em função das doses crescentes de $\mathrm{N}$, verificando-se na dose máxima aplicada o teor de $162 \mathrm{mg} \mathrm{kg}^{-1}$ de nitrato na matéria fresca (Figura 4). Esse resultado corresponde ao aumento de 3,9, em relação à testemunha. Com a dose de máxima eficiência econômica de $\mathrm{N}\left(322 \mathrm{~kg} \mathrm{ha}^{-1}\right)$ para produtividade de frutos de abobrinha, o teor de nitrato na matéria fresca dos frutos seria de $138 \mathrm{mg} \mathrm{kg}^{-1}$. O acúmulo de nitrato pelas plantas ocorre quando há excesso de absorção de nitrogênio em relação à capacidade de assimilação deste nutriente, uma vez que havendo $\mathrm{N}$ disponível no sistema para absorção, a planta tende a absorvê-lo além de sua demanda e estocá-lo nos vacúolos na forma de nitrato (MARSCHNER, 1995).

Os resultados nesse trabalho demonstram que a elevação na disponibilidade de $\mathrm{N}$ é um fator determinante no acúmulo de nitrato pelas plantas, reforçando o proposto na literatura por diversos autores. Incremento no teor de nitrato em função de doses de $\mathrm{N}$ tem sido preconizado na literatura para diferentes hortaliças, como repolho, espinafre (Chen et al., 2004), alface (PôRTO et al., 2008), tomate (FERreira et al., 2006), dentre outras.

Apesar do acúmulo de nitrato observado, o máximo teor de nitrato em frutos de abobrinha obtido nesse trabalho é bastante inferior aos preconizados na literatura para outras hortaliças, principalmente folhosas como alface, repolho e espinafre, dentre outras. Diversos trabalhos têm demonstrado que hortaliças folhosas tendem a acumular altos teores de nitratos em suas folhas (Fytianos e Zarogiannis, 1999; Beninni et al., 2002; Chen et al., 2004; Mantovani et al., 2005), enquanto em hortaliças de flores e frutos, geralmente, a tendência é de menos acúmulo de nitrato (Fytianos e Zarogiannis, 1999). As razóes estariam ligados ao fato de o $\mathrm{N}$, ao ascender no caule via corrente xilemática é, preferencialmente, dirigido às partes da planta com maior taxa transpiratória que são, normalmente, as folhas, justificando o fato de que as hortaliças folhosas tendem a ter maior risco de acumular elevados teores de nitrato (КROHN et al., 2003).

A Organização das Naçôes Unidas para Agricultura e Alimentação (FAO) e a Organização Mundial da Saúde (OMS) estabeleceram o limite de ingestão diária aceitável de nitrato pelo homem de $3,7 \mathrm{mg} \mathrm{kg}^{-1}$ de massa corporal (WHO, 1995). Considerando esse limite, e partindo do maior teor de nitrato encontrado nos frutos de abobrinha, de forma a desprezar a contribuição das demais fontes de nitrato para o homem, verifica-se que uma pessoa com $70 \mathrm{~kg}$ de massa corporal poderia consumir, diariamente, até $1,6 \mathrm{~kg}$ de frutos de abobrinha. Portanto, essa quantidade está bastante acima das estimativas de consumo de uma pessoa normal com essa condição corporal, demonstrando que o valor obtido na maior dose de $\mathrm{N}$ utilizada não forneceria risco à saúde humana.

\section{CONCLUSÃO}

É possível alcançar maior produtividade de frutos na cultura da abobrinha com a aplicação de maior dose de $\mathrm{N}$ do que a recomendada para Minas Gerais, permitindo melhor exploração do potencial produtivo da cultura.

A dose de máxima eficiência econômica de $\mathrm{N}$ para a produtividade da cultura da abobrinha é de $322 \mathrm{~kg} \mathrm{ha}^{-1}$, para $\mathrm{Y}=4,375$, com produtividade de frutos de aproximadamente $29,86 \mathrm{t} \mathrm{ha}^{-1}$.

Mesmo diante do emprego de doses elevadas de N, o acúmulo de nitrato em frutos de abobrinha alcança nível pouco provável de ser considerado indesejável ao consumo humano.

\section{AGRADECIMENTOS}

Ao CNPq, pela concessão da bolsa de estudos de DS ao primeiro autor e de produtividade em pesquisa para o segundo, terceiro e quarto autores. À FAPEMIG pelo apoio.

\section{REFERÊNCIAS}

ADDISCOTT, T.M.; BENJAMIN, N. Nitrate and human health. Soil and Use Manage, v.20, p.98-104, 2004.

ALVAREZ V., V.H.; NOVAIS, R.F.; BARROS, N.F.; CANTARUTTI, R.B.; LOPES, A.S. Interpretação dos resultados das análises de solos. In: RIBEIRO, A.C.; GUIMARES, H.; ALVAREZ V., V.H. (Ed.). Recomendaçóes para uso de corretivos e fertilizantes em Minas Gerais - 5. a Aproximação. Viçosa: CFSEMG, 1999. p.25-32.

ANDRADE JUNIOR, A.S.; DIAS, N.S.; FIGUEIREDO JUNIOR, L.G.M.; RIBEIRO, V.Q.; SAMPAIO, D.B. Produção e qualidade de frutos de melancia à aplicaçáo de nitrogênio via fertirrigação. Revista Brasileira de Engenharia Agrícola e Ambiental, v.10, p.836-841, 2006.

BENINNI, E.R.Y.; TAKAHASHI, H.W.; NEVES, C.S.V.J.; FONSECA, I.C.B. Teor de nitrato em alface cultivada em sistemas hidropônico e convencional. Horticultura Brasileira, v.20, p.183186, 2002.

BOINK, A.; SPEIJERS, G. Health effect of nitrates and nitrites, a review. Acta Horticulturae, n.563, p.29-36, 2001.

CARPES, R.H.; LÚCIO, A.D.; STORCK, L.; LOPES, S.J.; ZANARDO, B.; PALUDO, A.L. Ausência de frutos colhidos e suas interferências na variabilidade da fitomassa de frutos de abobrinha italiana cultivada em diferentes sistemas de irrigação. Revista Ceres, v.55, p. 590-595, 2008.

CARRIJO, I.V.; CORREIA, L.G.; TRANI, P.E. Abóbora italiana. In: RIBEIRO, A.C; GUIMARES, H.; ALVAREZ V., V.H. (Ed.). Recomendações para uso de corretivos e fertilizantes em Minas Gerais - 5. a Aproximação. Viçosa: CFSEMG, 1999. p.175. 
CATALDO, D.A.; HAROON, M.; SCHRADER, L.E.; YOUNGS, V.L. Rapid colorimetric determination of nitrate in plant tissue by nitration of salicylic acid. Communications in Soil Science and Plant Analysis, v.6, p.71-80, 1975.

CEASA-MG. Central de Abastecimento do Estado de Minas Gerais. Preços e ofertas de produtos. 2011. Disponível em: <http:// www.conab.gov.br>. Acesso em: 4/4/2011.

CHEN, B.M.; WANG, Z.H.; LI, S.X.; WANG, G.X.; SONG, H.X.; WANG, X.N. Effects of nitrate supply on plant growth, nitrate accumulation, metabolic nitrate concentration and nitrate reductase activity in three leafy vegetables. Plant Science, v.167, p.635-643, 2004.

COELHO, E.L.; FONTES, P.C.R.; FINGER, F.L.; CARDOSO, A.A. Qualidade do fruto de melão rendilhado em função de doses de nitrogênio. Bragantia, v.62, p.173-178, 2003.

CONAB. Companhia Nacional do Abastecimento. Preço dos insumos agropecuários. 2011. Disponível em: <http://www. ceasaminas.com.br/>. Acesso em: 4/4/2011.

FERREIRA, M.M.M.; FERREIRA, G.B.; FONTES, P.C.R.; DANTAS, J.P. Qualidade do tomate em função de doses de nitrogênio e da adubação orgânica em duas estações. Horticultura Brasileira, v.24, p.141-145, 2006.

FILGUEIRA, F.A.R. Novo manual de olericultura. 3.ed. Viçosa: Editora UFV, 2008. 421p.

FYTIANOS, K.; ZAROGIANNIS, P. Nitrate and nitrite accumulation in fresh vegetables from Greece. Bulletin of Environmental Contamination and Toxicology, v.62, p.187-192, 1999.

KROHN, N.G.; MISSIO, R.F.; ORTOLAN, M.L.; BURIN, A.; STEINMACHER, D.A.; LOPES, M.C. Teores de nitrato em folhas de alface em função do horário de coleta e do tipo de folha amostrada. Horticultura Brasileira, v.21, p.216-219, 2003.
MANTOVANI, J.R.; FERREIRA, M.E.; CRUZ, M.C.P. Produção de alface acúmulo de nitrato em função da adubação nitrogenada. Horticultura Brasileira, v.23, p.758-762, 2005.

MARSCHNER, H. Mineral nutrition of higher plant. 2.ed. New York: Academic Press, 1995. 889p.

OLIVEIRA, A.P.; OLIVEIRA, A.N.P.; ALVES, A.U.; ALVES, E.U.; SILVA, D.F.; SANTOS, R.R.; LEONARDO, F.A.P. Rendimento do maxixeiro adubado com doses de nitrogênio. Horticultura Brasileira, v.26, p.533-536. 2008.

PÔRTO, M.L.; ALVES, J.C.; SOUZA, A.P.; ARAUJO, R.C.; ARRUDA, J.A. Nitrate production and accumulation in lettuce as affected by mineral nitrogen supply and organic fertilization. Horticultura Brasileira, v.26, p.227-230, 2008.

PUIATTI, M.; SILVA, D.J.H. Abóboras e morangas. In: FONTES, P.C.R. (Ed.). Olericultura: teoria e prática. Viçosa: DFT - Setor de Olericultura/UFV, 2005. p.279-297.

QUEIROGA, R.C.F.; PUIATTI, M.; FONTES, P.C.R.; CECON, P.R.; FINGER, F.L. Influência de doses de nitrogênio na produtividade e qualidade do meláo Cantalupensis sob ambiente protegido. Horticultura Brasileira, v.25, p.550-556, 2007.

RAIJ, B.VAN. Fertilidade do solo e adubação. Piracicaba: Potafos, 1991. 343p.

SAEG. Sistema para Análises Estatísticas. Versão 9.1. Viçosa: Fundação Arthur Bernardes, 2007.

TURAZI, C.M.V.; JUNQUEIRA, A.M.R.; OLIVEIRA, S.A.; BORGO, L.A. Acúmulo de nitrato em alface em função da adubação, horário de colheita e tempo de armazenamento. Horticultura Brasileira, v.24, p.65-70, 2006.

WHO. World Health Organization. Evaluation of certain food additives and contaminants. (Forty-fourth report of the Joint FAO/ WHO Expert Committee on Food Additives). Geneva: FAO/WHO, 1995. 54p. (WHO Technical Report Series, 859) 